
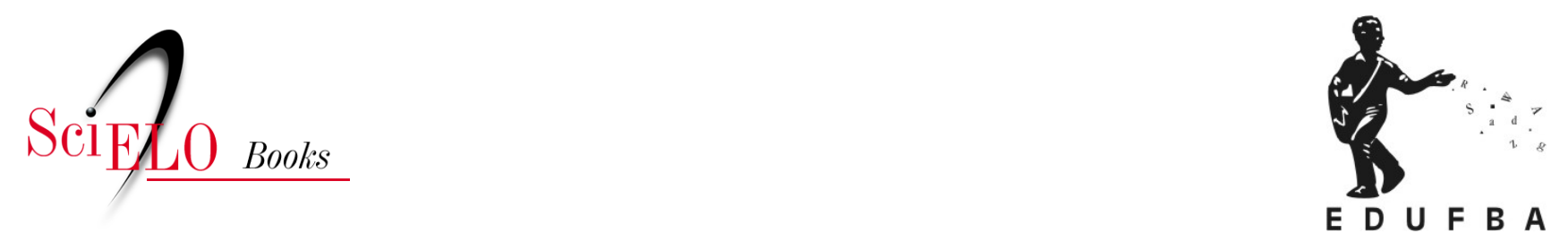

\title{
A versão brasileira da legislação Jim Crow o projeto de embranquecimento do direito de imigração e o direito costumeiro de segregação racial: um estudo de caso
}

\author{
Tanya Katerí Hernández \\ Arivaldo Santos de Souza \\ Luciana Carvalho Fonseca \\ (Tradutores)
}

\section{SciELO Books / SciELO Livros / SciELO Libros}

HERNÁNDEZ, T.K. A versão brasileira da legislação Jim Crow: o projeto de embranquecimento do direito de imigração e o direito costumeiro de segregação racial: um estudo de caso. In:

Subordinação racial no Brasil e na América Latina: o papel do Estado, o Direito Costumeiro e a Nova Resposta dos Direitos Civis [online]. Translated by Arivaldo Santos de Souza and Luciana Carvalho Fonseca. Salvador: EDUFBA, 2017, pp. 53-73. ISBN: 978-85-232-2015-0.

https://doi.org/10.7476/9788523220150.0005.

All the contents of this work, except where otherwise noted, is licensed under a Creative Commons Attribution 4.0 International license.

Todo o conteúdo deste trabalho, exceto quando houver ressalva, é publicado sob a licença Creative Commons Atribição $\underline{4.0}$. 


\section{A versão brasileira da legislação Jim Crow: o projeto de embranquecimento do direito de imigração e o direito costumeiro de segregação racial: um estudo de caso}

O Brasil foi o último país das Américas a emancipar seus escravos em 1888. Apesar da abolição da escravidão, o Brasil compartilhou do desinteresse latino-americano em integrar plenamente e conceder direitos subjetivos de cidadania aos seus habitantes negros. Esse foi um assunto que inquietou as elites brasileiras, levando-se em conta o significativo número de escravos que tinha sido importado para o país. De fato, mais de $90 \%$ dos aproximadamente 10 milhões de escravizados africanos trazidos para as Américas foram levados para a América Latina e para o Caribe, ao passo que apenas 4,6\% foram levados para os Estados Unidos. (MINTZ, 1974) Um historiador estima que o número total de escravos africanos importados para o Brasil foi de 3,6 milhões. (TAUNAY, 2001) Em contraste, historiadores estadunidenses estimam que apenas 500 mil escravos africanos foram importados para os Estados Unidos e América do Norte Britânica. (THOMAS, 1997, p. 500) A resposta brasileira para o medo gerado por uma população negra recém-liberta foi similar a do resto da América Latina: uma tentativa de embranquecer a população.

No Brasil, a filosofia do embranquecimento, chamada de "branqueamento”, foi diretamente comparável à filosofia de blanqueamiento da América 
Hispânica. Assim como o blanqueamiento na América Hispânica, o branqueamento no Brasil foi uma ideologia e um conjunto de práticas de embranquecimento da população brasileira e de suposta modernização da nação. Os esforços para embranquecer a população foram tão amplos na região que um acadêmico descreveu a América Latina como tendo uma "cultura de colono branco" que até hoje exerce influência, em oposição ao reconhecimento e inclusão integral dos não brancos. (GOTT, 2007, p. 269-289) O Brasil se destaca entre os países latino-americanos, tendo o mais amplo aparato legislativo para regular restritivamente a questão da raça no período pós-abolição da escravidão, e serve de caso de estudo útil por oferecer mais detalhes sobre o desenvolvimento do direito costumeiro de regulação racial.

\section{A regulação racial: 0 direito de imigração}

O primeiro passo na campanha nacional de embranquecimento foi arquitetar legislações de imigração restritivas para, em primeiro lugar, encorajar a imigração europeia e, em segundo lugar, proibir ou fortemente desestimular a imigração de pessoas de ascendência africana, asiática ou indígena. Ainda em 1850, com a crescente pressão internacional para abandonar o tráfico de escravos e abolir completamente a escravidão, o poder legislativo brasileiro tomou medidas decisivas para estimular a imigração europeia. (BUTLER, 1998, p. 26-27) Uma lei aprovada naquele ano ofereceu generosas concessões de terras para imigrantes com o fim de encorajar a vinda de um maior número de europeus. (PRUDENTE, 1989, p. 129-131) A mesma lei negava títulos de propriedade de terra para quilombolas. O governo da província de São Paulo financiou generosamente a Sociedade Promotora de Imigração. (HOLLOWAY, 1977, p. 163)

Depois da emancipação dos escravos em 1888 e da dissolução do Império brasileiro em 1889, a preferência legal por imigrantes brancos se tornaria ainda mais explícita, pois às elites desagradava a visão de descendentes de africanos como trabalhadores remunerados. (AZEVEDO, 1987, p. 252) As atas das reuniões oficiais de donos de plantações, os quais já esperavam pelo fim da escravidão, registraram a preferência por imigrantes brancos em vez da "indolência" da população nativa, de "raça decrépita", que trabalhava em servidão. (TRABALHOS, 1878, p. 155-159) A preferência por imigrantes europeus como racialmente motivada se torna clara ao se observar que os europeus recrutados não 
eram trabalhadores especializados, muitos eram camponeses analfabetos. (DOMINGUES, 2004, p. 89-91) Além do mais, no período posterior à abolição, quando imigrantes europeus estavam sendo procurados, os postos de trabalho assalariado disponíveis eram para trabalhadores pouco qualificados, sem educação ou treinamento profissional, que poderiam ter sido facilmente preenchidos pelos brasileiros recém-emancipados, se os mesmos não fossem vistos como racialmente inadequados para o trabalho pago. (KOWARICK, 1987, p. 118) Anúncios nos classificados dos periódicos explicitamente declaravam: "Preferimos brancos”. (DOMINGUES, 2004, p. 109-110) Essas atitudes racializadas sobre a capacidade de trabalhar como assalariado se refletiram nas assembleias legislativas regionais. $\mathrm{Na}$ assembleia legislativa paulista de 1888, a preferência por trabalhadores estrangeiros brancos foi discutida juntamente com a proposta de conceder terras para estimular a imigração. (SÃO PAULO, 1888, p. 32)

Consequentemente, um dos primeiros atos normativos da nova república foi o Decreto de Imigração ${ }^{0} 528$, promulgado em 28 de junho de 1890, pelo presidente provisório Manoel Deodoro da Fonseca. (PRUDENTE, 1989, p. 151-152) O decreto excluía todos os membros de populações indígenas da Ásia e da África da imigração para o Brasil. Isso ocorreu em um período em que a imigração em geral estava em seu auge e imigrantes de outros continentes, como da Europa, tinham permissão de entrada sem pagamento de taxa. Em 1921, o Congresso Brasileiro aprovou uma lei similar, na qual proibiu especificamente imigrantes negros de entrarem no Brasil. (BRASIL, 1921) Quando os negros tentavam imigrar para o país, eles simplesmente tinham seus vistos negados. (MEADE, 1996, p. 31) Tal fato precedeu a lei estadunidense de imigração por cotas segundo a origem nacional, de 1924, a qual explicitamente regulou a imigração de acordo com critérios de raça e origem étnica. Entretanto, uma das provisões instituídas foi relaxada dois anos depois, quando uma lei aprovada em 1892 permitiu a entrada de imigrantes chineses e japoneses. (PRUDENTE, 1989, p. 153-154) As grandes ondas de imigração no Brasil coincidiram com a abolição da escravidão em 1888, e a imigração europeia era uma política nacional no final do século XIX, tendo o Brasil um número de imigrantes inferior apenas ao da Argentina. (BLETZ, 2003, p. 22-23, 30) Ressalta-se que, em 1889, o Brasil aprovou uma lei para garantir a naturalização automática aos imigrantes de origem europeia. (BLETZ, 2003)

Além do mais, o governo usou dinheiro público, para encorajar a imigração europeia, no pagamento dos custos com transporte. O governo brasileiro 
arcou com o transporte de europeus para o Brasil, de 1851 a 1909, e a província de São Paulo (depois, estado) fez o mesmo, de 1881 a 1927. (BLETZ, 2003, p. 157-158) O direito administrativo paulista também oferecia subvenções para moradia, alimentação e serviços de saúde hospitalares (SÃO PAULO, 1887, art. 17, p. 7), além de oferecer auxílio financeiro em espécie, que variava conforme a idade do imigrante europeu. (SÃO PAULO, 1887) As despesas com imigração financiadas pelo estado de São Paulo também incluíam atividades de lobby pró-imigração nos países europeus de origem, bem como a cessão de ferramentas agrícolas e a dispensa de serviço militar para os filhos dos imigrantes. (DOMINGUES, 2004, p. 69) Em 1888, apenas alguns meses antes da abolição total da escravidão, a Assembleia Provincial de São Paulo autorizou o governo a alocar a grande variedade de subsídios para a imigração a um mínimo de cem mil imigrantes. (LOBO, 1924, p. 219) A alocação de recursos do governo para o projeto de branqueamento por meio da imigração europeia foi tão expressivo que em 1895 os subsídios para a imigração representavam 14,5\% do orçamento anual de São Paulo, 10\% do orçamento de 1896 e 10,8\% do orçamento de 1901. (SÃO PAULO, 1941, p. 6-22)

Enquanto as comportas eram abertas para imigrantes europeus, a proibição da entrada de imigrantes africanos foi interpretada extensivamente, a ponto de excluir turistas estadunidenses de ascendência africana que nunca haviam pisado na África e nem sequer eram cidadãos de países do continente africano. Além do mais, o governo brasileiro continuou a desprezar cidadãos estadunidenses de origem africana a despeito do flagrante descumprimento do Tratado de Paz, Amizade, Navegação e Comércio, de 1828, entre Brasil e Estados Unidos. Esse tratado declarava que "os cidadãos e súditos de ambos os países podem viajar de um país a outro, e têm direito de residir e fazer negócios [...]. Haverá uma paz e amizade perfeita, estável e inviolável entre [os Estados Unidos e o Brasil] em todas suas possessões e territórios”. (LESSER, 1994, p. 23-44)

A restrição racial no direito de imigração brasileiro continuou com o governo de Getúlio Vargas (1930-1945). Em 1934, a Nova Constituição efetivamente reservaria a possibilidade de imigração a brancos. (PRUDENTE, 1989, p. 155156) Isso foi feito estabelecendo um teto anual de $2 \%$ do número de imigrantes de acordo com a origem nacional daqueles que haviam chegado ao Brasil nos últimos 50 anos. Considerando o período, a imigração de africanos não era possível no Brasil. O dispositivo constitucional, estabelecendo a cota anual de $2 \%$, na prática, proibiu qualquer imigração africana sem ter que fazer menção à raça em 
seu texto. (BRASIL, 1934, art. 121, par. 6) A Constituição brasileira também proibiu colônias de negros ou asiáticos independentemente de sua origem nacional, por meio da proibição da concentração de imigrantes em qualquer parte do país quando houvesse possibilidade de conflito com o direito de regular a seleção de imigrantes e sua assimilação. (BRASIL, 1934, art. 121, par. 7) Essa medida foi presumivelmente elaborada para limitar a imigração de outros países latino-americanos. (PRUDENTE, 1989, p. 155-156) Provisões constitucionais, elaboradas para permitir que o governo impedisse imigrantes não brancos de entrar no país, foram adotadas na Constituição de 1946 e em um decreto de 1969 do governo militar. (BRASIL, 1946, art. 162)

O projeto de imigração para fins de branqueamento foi tão bem-sucedido que, em menos de um século de imigração europeia subsidiada, o Brasil importou mais trabalhadores brancos livres do que escravos negros em três séculos de tráfico de escravos (4.793.981 imigrantes chegaram entre 1851 e 1937, em comparação com os 3,6 milhões de escravos trazidos à força). (SANTOS; HALLEWELL, 2002, p. 70) Em São Paulo, onde a imigração europeia foi a mais intensa, a população de descendentes de africanos (pardos e pretos contados juntamente) diminuiu de $47 \%$ em 1811 e 1836 para $16 \%$ em 1928. (LOWRIE, 1938, p. 12)

Com uma política de imigração explicitamente baseada em raça, legisladores brasileiros e atores da elite manifestaram expressamente o desejo de usar a imigração para erradicar os negros. Assim como os projetos de branqueamento da América Hispânica, a imigração branca brasileira se fundava em um discurso eugenista que reforçava as crenças brasileiras preexistentes sobre a inferioridade de africanos e sua futura extinção definitiva. (SANTOS; HALLEWELL, 2002, p. 75) Por exemplo, em 1879, o parlamentar Joaquim Nabuco afirmou: "O negro e o branco, vivendo misturados socialmente durante séculos, o sangue preto naturalmente tenderá a ser eliminado no sangue branco, ou a desaparecer, cedendo essa raça o campo a outra mais preparada para a luta da vida". (NABUCO, 1983, p. 182)

À medida que aumentou o número de imigrantes europeus, também cresceu o apoio público de intelectuais à eugenia. Em 1912, um intelectual da elite, João Batista Lacerda, que estava presente no primeiro Congresso Universal das Raças, de 1911, previu que, em 2012, a população brasileira seria composta por $80 \%$ de brancos, $3 \%$ de mestiços e $17 \%$ de indígenas; não haveria negros. (SKIDMORE, 1974, p. 67) A previsão de Lacerda foi, aparentemente, apoiada 
por uma análise oficial do censo brasileiro. Apesar de a questão de raça/cor ter sido omitida dos censos de 1900 e 1920, o renomado teórico social Oliveira Vianna escreveu um artigo oficial, em 1920, anunciando que já havia ocorrido uma rápida diminuição do "coeficiente de sangue inferior" no patrimônio genético brasileiro. (VIANNA, 1922) Depois disso, o censo e outros instrumentos públicos com dados estatísticos seriam o veículo para branquear a imagem nacional. $\mathrm{O}$ embranquecimento simbólico da população foi facilitado por um decreto de 14 de dezembro de 1890 do ministro da Fazenda, Rui Barbosa, que ordenava a destruição de todos os documentos do Ministério da Fazenda relacionados à escravidão (escrituras, diários de bordo, documentos religiosos). (LACOMBE, 1988) O Congresso Nacional ratificou o decreto de Barbosa em 20 de dezembro de 1890. Como abolicionista, o ministro Barbosa queria remover a "mancha negra" do passado escravista brasileiro. (BRASIL, 1891) Contudo, o decreto também dificultou a investigação das origens africanas de muitos brasileiros "brancos".

Dada a interpretação do direito de imigração e da política imigratória altamente baseada em raça, como pode ser explicado o grande número de imigrantes japoneses que chegaram ao Brasil a partir de 1908? Quase 250 mil japoneses se estabeleceram no Brasil em um período de 60 anos, entre 1908 e 1968. (MAKABE, 1999, p. 702-723) A população é a maior comunidade japonesa fora do Japão, com exceção da Manchúria. (MASTERSON; FUNADA-CLASSEN, 2004, p. 73) Com o estabelecimento dessa população, principalmente na região de São Paulo, sua presença foi facilmente percebida e não estava de acordo com o discurso eugenista predominante na época. Como essa mudança populacional foi possível?

A conjunção da demanda da economia cafeeira por mão de obra barata e da crise socioeconômica japonesa da década de 1920, juntamente com a proibição estadunidense de 1907 ao ingresso de imigrantes japoneses naquele país, influenciou a vinda de grandes números de japoneses imigrantes. (ESTADOS UNIDOS, 1907, 1917, 1924) Com a proibição de ingresso nos Estados Unidos a partir de 1907, o governo japonês procurou destinos alternativos para seus trabalhadores agrícolas, como a Argentina, o Peru e o México, e também o Brasil. (MASTERSON; FUNADA-CLASSEN, 2004, p. 5) O governo japonês arcou com o transporte e outras despesas dos imigrantes, além de negociar empregos em plantações e habitação para as famílias. As regras brasileiras exigiam que pelo menos três agricultores fisicamente capazes em uma família 
migrassem de uma vez para garantir o início imediato da produção agrícola. (MAKABE, 1999, p. 721)

$\mathrm{O}$ interesse da economia cafeeira no trabalho de agricultores japoneses foi tão grande que alguns caracterizaram os imigrantes como culturalmente brancos devido à sua superioridade em relação aos afro-brasileiros "nativos”. Por exemplo, em 1925, o congressista Oliveira Botelho afirmou:

Os turcos e sírios de pele branca e boa aparência física, imigrantes voluntários, preocupam-se apenas com o comércio e não saem das cidades. O clamor agrícola por braços fortes nunca nos perdoará se, por pretextos fúteis, nós impedirmos esse desenvolvimento. [...] Se os 30 milhões de brasileiros produzirem a mesma proporção de $30 \mathrm{mil}$ trabalhadores japoneses aqui, o Brasil será o país mais rico no mundo. (BUTLER, 1998, p. 37)

Mesmo com as limitações constitucionais estabelecidas por Vargas sobre a imigração de não brancos, em 1934, um deputado federal afirmou que "os colonos japoneses são ainda mais brancos que os portugueses (com sua contribuição para a branquitude do crescimento econômico e produção doméstica)”. (LESSER, 2000, p. 1-12) Tais perspectivas foram corroboradas pelo investimento dos próprios imigrantes japoneses na promoção midiática da sua branquitude. Jornais, revistas e livros regularmente publicavam fotografias de crianças com "cara de brasileiro”, eram filhos de pais japoneses e brasileiros brancos. (LESSER, 1999, p. 105) Essas fotografias parecem sugerir que os japoneses eram os candidatos ideais para a mestiçagem capaz de resultar em branquitude mais imediatamente. Os japoneses não foram literalmente considerados brancos, mas os proprietários de terra que apoiaram sua entrada certamente os consideravam superiores aos trabalhadores afro-brasileiros. (LESSER, 1994, p. 23-44)

Sem dúvida, durante o período da Segunda Guerra Mundial, as vozes daqueles que fizeram oposição à imigração não branca dos japoneses conseguiram ter mais espaço público. Apesar disso, o Brasil não implementou um plano de evacuação em massa ou reassentamento de seus residentes japoneses, como fizeram os Estados Unidos durante a guerra. Os brasileiros de ascendência japonesa puderam continuar suas atividades laborais e negócios sem interrupções porque, àquela altura, grande parte do país dependia de sua produção agrícola. (MAKABE, 1999, p. 709) Em vez de isolar toda a comunidade japonesa, foi lançada uma campanha para "abrasileirar” os residentes japoneses. Os jornais e as escolas em 
línguas estrangeiras foram proibidos, leis proibiram o uso da língua japonesa em espaços públicos e nomes próprios japoneses foram obrigados a serem cristianizados. (AUGELLI, 1958, p. 3-19) Em resumo, enquanto um complexo conjunto de circunstâncias influenciou a migração em larga escala de japoneses para o Brasil, sua presença nunca ameaçou a valorização nacional da branquitude. Em 1975, um grande banco brasileiro lançou uma campanha publicitária com a seguinte frase: "Precisamos de mais brasileiros como os japoneses". (LESSER, 2000, p. 11) O anúncio foi bem recebido e continuou a circular por mais de 25 anos.

\section{Segregação do mercado de trabalho}

Se os negros não foram completamente erradicados da população brasileira, a política de branqueamento foi bem-sucedida na medida em que os escravos recém-libertos e seus descendentes foram propositalmente preteridos no mercado de trabalho em razão da importação de imigrantes europeus. Nenhum suporte ou garantia social de qualquer tipo foi oferecido para ajudar os antigos escravos a ingressarem no mercado de trabalho depois de sua libertação. Embora seja verdade que o estado da Bahia aprovou uma lei de distribuição de terras não baseada em critérios raciais em 1897, a qual poderia teoricamente possibilitar afro-brasileiros recém-libertados e outros a terem acesso às escrituras de pequenas propriedades, também é verdade que os escravos libertos encontraram muitos obstáculos que os impediram de obter esses títulos em grande quantidade. (MAHONY, 1998, p. 90-116)

Além do mais, os afro-brasileiros foram sistematicamente excluídos do mercado de trabalho. Por exemplo, sabe-se que depois da emancipação as forças navais excluíram os afro-brasileiros dos postos de oficiais, até o ponto em que a imprensa popular passou a se referir à cor de pele branca como requisito de admissão. Os periódicos de 1910 até 1923 estão repletos de relatos sobre a preferência por candidatos que fossem "o mais branco possível" para o serviço militar. (NASCIMENTO, 2007, p. 283-311)

Na mesma linha, em uma sessão legislativa de 1928, em São Paulo, sobre a possível aprovação de uma lei que acabava com a proibição do ingresso de afro-brasileiros na polícia local, assinalou-se que afro-brasileiros não poderiam ser admitidos como carcereiros ou policiais militares. (SÃO PAULO, 1928, p. 351) E, mesmo depois da aprovação da referida lei, ainda em 1928, a pele branca continuou a ser incluída como um requisito oficial para os candidatos 
quando solicitavam os documentos de ingresso. (DOMINGUES, 2004, p. 137) Os afro-brasileiros só puderam entrar na polícia depois de 1932.

Em uma lista de ocupações em São Paulo (com mais de 50\% dos imigrantes) elaborada em 1894, no pós-abolição, os trabalhadores estrangeiros representavam 82,5\% das ocupações essenciais à rápida expansão urbana e industrialização (manufaturas, ofícios, transporte, comércio), ao passo que os negros foram relegados à esfera do trabalho doméstico. Somente em São Paulo, 71,2\% dos trabalhadores naquele período eram estrangeiros. (REID ANDREWS, 1988, p. 491-524) Além do mais, nas áreas rurais que conseguiram atrair trabalhadores imigrantes em número suficiente, os imigrantes brancos também eram preferidos em detrimento dos negros emancipados. De fato, o ministro da Agricultura, Antônio Prado, propôs medidas para promover o estabelecimento de imigrantes na agricultura. (FERNANDES, 1971, p. 19) A preferência por imigrantes brancos também é demonstrada no estudo de Sam Adamo sobre práticas empregatícias no Rio de Janeiro da década de 1930. Adamo descobriu que os trabalhadores imigrantes brancos de baixa qualificação eram preferidos em detrimento dos afrodescendentes mais bem educados, ainda que os afrodescendentes recebessem menos. (ADAMO 1983, p. 62-80)

\section{A segregação racial por meio do direito costumeiro: a construção de espaços brancos}

Em São Paulo, o coração do projeto nacional de imigração para o branqueamento, os afro-brasileiros enfrentaram a exclusão e a segregação racial por obra do direito e dos costumes. O desejo por espaços brancos acompanhou o projeto de embranquecimento da população. Ao contrário do Nordeste, onde os afro-brasileiros constituem parcela significativa da população, em São Paulo e outras regiões do sul do Brasil, os afro-brasileiros eram minoria. A população afro-brasileira de São Paulo em 1886, dois anos antes da abolição, era de $24 \%$, e diminuiu para 16\% em 1928. (DOMINGUES, 2004, p. 188) Em contraste, em 1890, 61,4\% da população da cidade de Salvador era de afro-brasileiros, esse número aumentou para 64,9\% em 1940. (BUTLER, 1998, p. 134) Mesmo se relativizarmos a exatidão dos números do censo devido à maleabilidade política dos mesmos, o contraste entre o norte e o sul permanece se considerarmos a proporção relativa de afro-brasileiros por região. Desse modo, São Paulo e outras regiões do sul com menos afro-brasileiros estavam em melhor posição para usar o direito costumeiro para segregar os afro-brasileiros dos brancos. 
Isso ocorreu na década de 1920, com a indicação oral de ruas separadas para negros e brancos em São Paulo. (DOMINGUES, 2004, p. 157-162) Um conjunto de depoimentos orais de afro-brasileiros no período pós-abolição no sul do Brasil revelou reiteradamente os costumes arraigados de segregação racial em ruas, praças, jardins e parques públicos, tanto nas capitais como nas cidades do interior. Tais regras costumeiras voltadas à segregação racial em espaços públicos foram aplicadas pela polícia local, a qual prendia os afro-brasileiros que as violassem.

Os registros da história oral não narram nenhuma ação judicial contestando essas práticas prisionais. Na medida em que algum afro-brasileiro ousasse desafiar as prisões feitas pela polícia por violação das regras de segregação, os denunciantes teriam que enfrentar o difícil obstáculo da tradição brasileira de aplicar o direito costumeiro. A lei colonial de 1769, a Lei da Boa Razão, autorizava a aplicação legal de costumes sociais de uso prolongado. (SILVA, 2004, p. 6) Tais costumes tinham a força de direito (TELLES, 1824) e continuaram a ter essa força no período após a independência e também nos dias de hoje. (HADDAD, 2007) Deter os afro-brasileiros que invadiam os espaços socialmente designados aos brancos foi um costume com força de lei. Tendo em vista a imagem predominante do Brasil como uma nação sem uma versão própria das leis de segregação racial Jim Crow estadunidenses, é necessário rever essa visão para que se leve em conta as experiências regionais de segregação racial e seu caráter de direito costumeiro.

Locais abertos ao público também praticavam a segregação racial. Restaurantes paulistanos simplesmente se negavam a atender os afro-brasileiros que se atrevessem a entrar em restaurantes socialmente designados para brancos. Anúncios de casas estampavam: "Pessoas de cor não são aceitas", ou a frase racialmente codificada "Preferimos estrangeiros". Quando se encontravam afro-brasileiros vivendo perto de brancos, eram famílias numerosas de imigrantes que alugavam quartos e porões a afro-brasileiros para conseguirem uma renda extra. (BUTLER, 1998, p. 76) Os jornais afro-brasileiros da época noticiavam a recusa de atender clientes negros por parte de barbearias, hospitais e de muitos outros lugares de acesso público, bem como lojas. Na região de Campinas, avisos de "somente brancos" eram usados em teatros e outros lugares públicos. (NASCIMENTO, 1980, p. 206) Há relatos de segregação racial similares em cidades do interior do Rio de Janeiro.

Registros da polícia do Rio de Janeiro do tempo da abolição da escravidão até a década de 1890 revelam numerosos casos de afro-brasileiros detidos 
pela polícia simplesmente porque caminhavam durante a noite. (CHALHOUB, 1988, p. 83-105) Uma grande porcentagem de crimes reportados nessa época foi de crimes contra a ordem pública, tais como vadiagem, que eram usados para marginalizar afrodescendentes. (ADAMO, 1983, p. 228-242) Os registros policiais também indicam que acusações de vadiagem não serviam para condenar os afro-brasileiros, mas para rotulá-los de "indivíduos criminosos". (CUNHA, 2005, p. 295-315) De modo similar, na cidade de Rio Claro, a lei de vadiagem foi usada para impedir a presença de não brancos em espaços públicos "brancos” na tentativa de manter os recém-libertos em uma posição de subjugação. (DEAN, 1976, p. 151) Os recém-libertos foram segregados residencialmente do centro de Rio Claro e foram proibidos de passearem nos arredores da praça de Rio Claro.

Em Vasália, uma pequena cidade no noroeste do interior do Rio de Janeiro, os habitantes se recordam de uma "segregação ao estilo Jim Crow na rua principal, em lojas, passeios públicos, clubes sociais, danceterias e concursos de beleza, que durou até o recente ano de 1985”. (TWINE, 1998, p. 120) Na própria cidade do Rio de Janeiro, o governo redesenhou a cidade para limpá-la dos moradores afro-brasileiros. Com o seu "Primeiro Plano de Embelezamento e Saneamento do Rio de Janeiro", a capital foi reconstruída para a criação de uma "Paris tropical”. (JOHNSON, 2001, p. 23) Setecentos e sessenta edifícios na região central foram destruídos para deslocar os afro-brasileiros para regiões menos visíveis. O governo do Rio de Janeiro não queria afro-brasileiros vivendo no espaço que deveria parecer com a Europa "branca”. A racialização do espaço inaugurou um período de remoção de bairros informais que durou décadas e empurrou os afro-brasileiros para a periferia, onde não havia serviços públicos. (MEADE, 1996) Com efeito, o Rio se tornou duas cidades separadas em virtude de raça e classe. Similarmente, o governo federal também encorajou a racialização do espaço por meio da utilização de uma política de "somente brancos" no recrutamento de diplomatas e enviados especiais para missões no exterior, de modo que o Brasil fosse representado como uma nação branca. (SKIDMORE, 1990, p. 12)

\section{O projeto estatal de embranquecimento pela educação pública}

Assim como a política estatal de imigração foi orientada pelas noções de hierarquia racial eugênica, o modelo estatal de educação no período pós-abolição foi influenciado de forma parecida. O trabalho de Jerry Dávila detalha o modo pelo qual a elite nacional de cientistas associados à eugenia liderou e implementou 
várias iniciativas locais escolares que procuravam mitigar as deficiências de crianças afro-brasileiras e indígenas entre 1917 e 1945. (DÁVILA, 2003, p. 25) A despeito de o desenvolvimento de um sistema de educação pública ter sido concebido como mecanismo para qualificar todas as crianças igualmente com o fim de modernizar a nação, o sistema reproduziu hierarquias raciais preexistentes ao tentar embranquecer a população culturalmente. Gestores escolares e professores receberam formação em teorias culturais e comportamentais que explicavam as fraquezas raciais e as políticas eugenistas que as corrigiriam. Os preconceitos raciais de educadores brasileiros poderiam ser bastante manifestos, como os de Everardo Backheuser, que, em 1926, declarou que a diversidade racial na escola primária seria prejudicial ao país. (HENTSCHKE, 2007, p. 209)

A estruturação eugênica da educação pública começou no Rio de Janeiro em 1917. À época, o estado do Rio de Janeiro possuía o maior sistema escolar do país, o qual serviu de paradigma e foi adotado por outras regiões que frequentemente recebiam recursos federais para implementar o modelo. A Secretaria de Educação do Rio de Janeiro divulgava seus achados em uma revista quadrimestral distribuída aos professores de todo o país. Além do mais, o ministro de Educação e Saúde Pública deu carta branca para os eugenistas no Rio de Janeiro desenvolverem políticas e programas que, segundo eles, tivessem base científica. As políticas educacionais eugenistas incluíam segregação de estudantes por QI e "estado de saúde", além da implementação das equipes de inspeção ou das "brigadas de saúde”. Em 1958, a reforma eugênica do sistema público de ensino foi codificada através da Lei de Diretrizes e Bases da Educação, que foi mantida com pequenas alterações pelo legislativo em 1996. (BRASIL, 1996)

Para começar, estudantes foram segregados em salas de aula diferentes conforme sua capacidade intelectual medida pelos testes-padrão de QI com vieses raciais (os testes de QI desenvolvidos nos EUA foram aplicados no Brasil). As crianças de baixa capacidade não aprendiam a ler no primeiro ano, mas aprendiam a se "adaptar à vida escolar" com instruções sobre higiene pessoal. A medida era uma cilada para os estudantes afro-brasileiros na primeira série porque a falta de instrução acadêmica fazia com que os mesmos repetissem a primeira série até que, de alguma maneira, aprendessem a ler ou simplesmente abandonassem a escola por frustração.

Alunos também eram segregados ou completamente afastados da escola por conta do "estado de saúde" comprometido, o que favorecia a exclusão de crianças afro-brasileiras das séries adequadas ou da educação formal como um 
todo. Saúde comprometida incluía: sífilis, parasitas, adenopatias, anemia e indiferença à educação ou comportamento antissocial, presumivelmente, resultado de características hereditárias ou razões culturais. Tais estudantes eram frequentemente afastados da escola sob o pretexto de que eles colocariam em risco a saúde daqueles considerados aptos para aprender. A repetência era considerada um sintoma de doença.

As poucas crianças afro-brasileiras que conseguiam superar as barreiras de entrada e exclusão diária foram expostas a programas que procuravam mitigar suas más condições raciais e a programas de embranquecimento cultural. O programa mais importante do gênero era a "brigada de saúde”, que foi criada para melhorar os alunos eugenicamente. As brigadas de saúde, organizadas em cada sala de aula, contavam com um estudante responsável por inspecionar a higiene dos colegas diariamente e fazer o respectivo registro em um quadro afixado na porta da sala de aula. Aqueles estudantes com higiene ruim (inevitavelmente os afro-brasileiros) eram enviados à diretoria para uma aula extra de higiene em vez de receber o ensino regular em sala de aula. Portanto, em vez de ensino acadêmico, os alunos afro-brasileiros eram submetidos à instrução de como lavar o rosto, orelhas, cabelo; escovar os dentes; aparar as unhas e lustrar os sapatos. Consequentemente, as crianças afro-brasileiras recebiam noções rudimentares de leitura, e quando recebiam, apenas na terceira série, pois os educadores, até então, enfocavam o ensino de hábitos de higiene para que essas crianças melhorassem eugenicamente para a sociedade. Além disso, programas musicais europeus foram instituídos para civilizar os estudantes não brancos e encorajá-los a abandonar a degenerada música carnavalesca de matriz africana.

As crianças afrodescendentes que realmente tiveram alguma exposição a um conteúdo acadêmico sofriam agressões por meio de livros didáticos com conteúdo preconceituoso. (NAVA, 1998, p. 39-63) Por exemplo, ainda no ano de 1964, o livro didático oficial para geografia e história do Brasil afirmava que "de todas as raças, a raça branca é a mais inteligente, perseverante e empreendedora [...] a raça negra é muito mais atrasada do que as outras”. (HENTSCHKE, 2007, p. 142)

O embranquecimento da educação também implicava a exclusão de afro-brasileiros da carreira docente. Ainda que houvesse professores afro-brasileiros durante as primeiras duas décadas do século XX, os quais haviam recebido instrução de instituições religiosas, esse quadro foi alterado pelas reformas educacionais levadas a cabo pelo governo do Rio de Janeiro. Desde 1917, para 
se tornar professor, era necessário um curso específico formatado de maneira similar aos cursos universitários de ciências sociais. Antes desse período, um diploma de ensino médio era suficiente para lecionar em uma escola primária em qualquer lugar do Brasil. Os afro-brasileiros inevitavelmente encontraram dificuldades de obter esse novo título. $\mathrm{O}$ treinamento profissional oferecido na "escola normal", inspirado no modelo do Columbia Teachers College, exigia um exame de admissão tão rigoroso que os candidatos faziam um curso preparatório com um ano de duração em uma escola privada. Tais cursos preparatórios estavam fora do alcance financeiro da maioria dos afro-brasileiros, que possuíam resultados insatisfatórios, os quais, por sua vez, confirmariam a presumida deficiência de candidatos afro-brasileiros. Testes psicológicos dos candidatos também foram empregados para confirmar a inaptidão para educar decorrente da raça. Além disso, também se exigia que os candidatos tivessem determinado peso e altura, os quais, de forma eugênica, correspondiam a um tipo de corpo o mais próximo possível dos padrões europeus. Como resultado, o educador médio de escola pública passou a ser a mulher branca de classe média, treinada para conceber seus alunos dentro de uma perspectiva racial. (DÁVILA, 2003)

Os poucos estudantes afro-brasileiros afortunados o bastante para conseguir que algum branco patrocinasse sua educação em uma escola privada corriam o risco de não serem admitidos por razões administrativas, pois outros pais poderiam retirar seus filhos como forma de protesto. (HENTSCHKE, 2007, p. 143) Dessa maneira, as escolas privadas preservariam sua exclusividade branca, enquanto os afrodescendentes eram mantidos segregados nas problemáticas escolas públicas primárias.

\section{Regulação de religiōes de matriz africana como branqueamento}

Assim como fez no sistema público de educação, o governo brasileiro também implementou seu projeto de branqueamento por meio de uma opressiva regulação das práticas religiosas de matriz africana. Após a independência e a abolição da escravidão, o Brasil decretou a separação entre a Igreja e o Estado em 7 de janeiro de 1890 . O artigo $2^{\circ}$ do Decreto 119-A dispunha que "a todas as confissões religiosas pertence por igual a faculdade de exercerem o seu culto, regerem-se segundo a sua fé e não serem contrariadas nos atos particulares ou públicos, que interessem o exercício deste decreto”. (JOHNSON, 2001, p. 23) 
Todavia, a despeito do decreto, grupos religiosos de matriz africana foram alvo de intenso escrutínio governamental por meio do direito penal e administrativo. A situação não mudou quando as provisões do decreto de liberdade religiosa foram incorporadas à Constituição de 1891.

O Código Penal de 1890 continha novos artigos que foram usados para tornar ineficaz o direito de liberdade religiosa para grupos religiosos de matriz africana. (MAGGIE, 1992, p. 22-23) O artigo 157 proibia "Praticar o espiritismo, a magia e seus sortilégios, usar de talismãs e cartomancias para despertar sentimentos de ódio ou amor, inculcar cura de moléstias curáveis ou incuráveis, enfim, para fascinar e subjugar a credulidade pública”. O artigo 158 proibia "Ministrar, ou simplesmente prescrever, como meio curativo para uso interno ou externo, e sob qualquer forma preparada, substância de qualquer dos reinos da natureza, fazendo, ou exercendo assim, o oficio do denominado curandeiro". Além disso, a Lei ${ }^{\circ} 173$, aprovada em 1893, garantia direitos apenas às associações religiosas oficialmente registradas e que não promovessem fins ilícitos ou imorais. Todas essas provisões legais foram usadas em conjunto para impedir práticas religiosas de matriz africana consideradas algo socialmente nocivo e uma ameaça à saúde pública, sob os auspícios do Serviço de Higiene Administrativa da União. Essa orientação estava em conformidade com a concepção geral de que os afro-brasileiros constituíam um problema de higiene social para o país. (TROCHIM, 1988, p. 285-300)

As religiões de matriz africana eram tratadas como magia ilegal e efetivamente não abrangidas pelo conceito de religião, fazendo com que a prática religiosa oficial brasileira e a identidade nacional fossem brancas. Como consequência, forças policiais invadiam e destruíam centros religiosos de matriz africana (terreiros de candomblé, centros de macumba, umbanda, xangô, tambor de Minas e espiritismo), além disso, assediavam e prendiam os praticantes e confiscavam seus objetos ritualísticos.

Mesmo a região Nordeste, predominantemente negra, sofreu perseguição policial. (BASTIDE, 1978, p. 164) E, na Bahia, agentes do governo chegaram ao ponto de, em 1902, proibir os tambores de clara origem africana nas festas profanas de Carnaval. (FRY; CARRARA; MARTINS-COSTA, 1988, p. 259) A elite baiana preocupada há muito tempo em ser vista pelo resto do país como "os brancos da Bahia", ou seja, menos brancos por causa da desconfiança de que seus ancestrais seriam mestiços em um Nordeste predominantemente negro. Provavelmente, a insegurança da elite baiana, devido ao questionamento 
nacional de sua branquitude, exacerbou o desejo de dissociarem-se da cultura e religião de matriz africana. (BUTLER, 1998, p. 185)

A regulação de religiões de matriz africana se modificou pouco durante o regime de Getúlio Vargas (1930-1945), que buscava uma imagem de unidade nacional. Enquanto o Decreto Presidencial n ${ }^{\circ} 1202$ de Vargas reconhecia a legitimidade de casas tradicionais de candomblé praticarem seu culto, deixou para a polícia a responsabilidade de distinguir os grupos que não eram "tradicionais”, considerados praticantes de bruxaria, magia e curas fraudulentas. O requerimento que grupos religiosos faziam ao Estado os tornava particularmente vulneráveis à regulação e à perseguição policial. (similarmente, leis baianas de 1932 declararam que capoeiristas eram "delinquentes perigosos", sujeitando-os à perseguição policial). (BUTLER, 1998, p. 187) De fato, um departamento policial inteiro ("Polícia de Costumes") foi criado por Vargas, em 1934, para regular e distinguir as práticas religiosas legítimas das práticas ilegais. O registro federal das religiões no Departamento de Costumes só deixou de ser obrigatório em 1974, fazendo com que os praticantes de religiões de matriz africana fossem marginalizados em uma nação idealizada como branca, representada pela famosa estátua do Cristo branco no topo do Corcovado, inaugurada em 1931.

O ápice das várias faces do projeto estatal de branqueamento foi o visível embranquecimento da região sul do Brasil. Porém, o interesse em continuar a busca por imigrantes europeus diminuiu devido à crescente atividade sindical desenvolvida por eles. A atividade sindical dos europeus imigrantes foi significativa e os movimentos grevistas foram numerosos entre 1917 e 1920. (MARAM, 1979, p. 215-223) Ainda que as elites governantes fossem relutantes em deportar os imigrantes, nos quais muito dinheiro foi investido para que viessem ao Brasil, elas decidiram finalmente suspender o programa de estímulos à imigração em 1927. (MARAM, 1977, p. 254-272) A esse programa, seguiram, em 1931, as restrições impostas pelo governo federal à imigração, bem como ao emprego de estrangeiros no comércio e na indústria, nos termos do Decreto n. 20.921. (BRASIL, 1931)

\section{Do branqueamento à mestiçagem}

Sem o afluxo de mais imigrantes europeus, o Brasil continuou tendo uma população nacional de ancestralidade visivelmente africana e indígena. O desejo do Estado Nacional de promover uma imagem internacional de civilização (a 
despeito da presença daqueles considerados racialmente não civilizados) despertou o interesse do governo em relação às teorias do sociólogo brasileiro Gilberto Freyre, um filho da elite branca do Nordeste mestiço.

As obras publicadas por Freyre entre 1930 e 1970 representaram um deslocamento conceitual do branqueamento sem jamais questionar a crença na superioridade branca. Freyre (1936) descreveu o desenvolvimento do Brasil como um conjunto de encontros íntimos entre as raças do qual resultou a criação de uma nova raça. Através da mestiçagem - mistura racial - foi criada uma "raça brasileira", que por sua vez presumia a inexistência de conflitos raciais na sociedade. A cultura brasileira também era resultado da mistura racial, mas Freyre considerava a contribuição europeia como a mais evidente e importante. Desse modo, a ideia de mestiçagem se assemelha ao discurso de mestizaje da América Hispânica e à descrição de José Vasconcelos de uma "raça cósmica", racialmente mista, mas essencialmente branca como discutido no capítulo anterior.

Apesar de Freyre ter usado o termo "racial democracy" (democracia racial) em algumas palestras e declarações a um público falante de inglês com o objetivo de descrever o caminho adotado pelo Brasil rumo à mestiçagem, ele não criou o termo. De fato, o reconhecido historiador George Reid Andrews observou que escritores e intelectuais brasileiros já discutiam a questão da democracia racial desde a década de 1880. (REID ANDREWS, 1996, p. 488) Contudo, foram talvez as publicações de 1965 do sociólogo brasileiro Florestan Fernandes, posteriormente traduzidas para o inglês em 1971, questionando o "mito da democracia racial", que deram ao termo uma maior difusão acadêmica. (FERNANDES, 1971, p. 137) Apesar disso, Freyre é amplamente reconhecido como o autor da tese da mistura racial que hoje se conhece como "democracia racial". (LEHMANN, 2008, p. 209-210) Pode ser que o entusiasmo do governo brasileiro pelas ideias de Freyre tenha levado à associação entre Freyre e o termo "democracia racial".

O discurso populista do regime de Getúlio Vargas (1930-1945) se ajustava bem à ideologia de mestiçagem de Gilberto Freyre, que foi diretamente incorporada aos projetos de construção nacional do governo. A mestiçagem foi considerada a verdadeira nacionalidade do brasileiro e foi promovida em solenidades públicas, escolas, universidades e na mídia nacional. (REID ANDREWS, 1996, p. 488) Quando Vargas se consolidou no poder como ditador, em 1937, aboliu todos os partidos políticos, incluindo a Frente Negra Brasileira, a qual tinha se organizado como um partido em 1930 e se registrado oficialmente em 
1936. (SKIDMORE, 1967) Além disso, o censo novamente se tornou o local de validação da ideologia racial do governo.

Assim como os dados eram empregados para validar a política de branqueamento da população, com a mudança para a política da mestiçagem, os dados do censo foram usados para exaltar a proeminência da mistura racial. Com frequência, isso foi feito de forma dissociada dos dados estatísticos reais a respeito da raça da população. Por exemplo, no censo de 1940, os resultados foram apresentados com um relatório elaborado para ressaltar o progresso da nova raça brasileira. (AZEVEDO, 1950, p. 33) Contudo, a nova raça mista brasileira foi celebrada no relatório do censo como um indicador de como "negros e indígenas continuam a desaparecer" no constante processo de seleção social e biológica, e que a imigração, especialmente a de origem mediterrânea, continua. O homem branco não apenas terá no Brasil um espaço privilegiado para a vida e cultura nos trópicos, mas poderá conectar-se com a velha Europa, cidadela da raça branca. (AZEVEDO, 1950, p. 41) A precisão das previsões comparativas dos relatórios do censo, claro, não podia ser aferida, já que o censo não foi realizado em 1930 ou 1910, e a questão sobre cor/raça ficou fora do censo de 1920. Além do mais, pelo menos um demógrafo sugeriu que as estatísticas raciais no Brasil foram por vezes intencionalmente alteradas para indicar uma população mais branca. Por exemplo, em uma publicação de 1940, Samuel Lowrie observou que, em termos absolutos, a população negra de São Paulo estava, na verdade, aumentando, a despeito de muitos de seus membros terem sido estatisticamente transferidos da categoria racial negra para branca. (LOWRIE, 1942, p. 398-416)

No censo de 1950, com a mudança na metodologia do recenseamento, em vez de serem listadas as categorias de cor, os cidadãos deveriam autodeclarar-se, tendo assim em suas mãos o poder do embranquecimento simbólico. Consequentemente, não foi surpresa quando o censo de 1950 indicou uma diminuição de 3,6\% no número de negros em relação a 1940, e um aumento de 5,3\% no número de pardos (categoria que inclui não apenas mestiços, mas também descendentes de indígenas). (NOBLES, 2000, p. 105) Novamente, o relatório do censo publicado celebrou o progresso da nação no caminho do embranquecimento da população por meio da mestiçagem. (BRASIL, 1970, p. 169)

Enquanto os dados raciais do censo de 1960 nunca foram totalmente divulgados, o regime militar, que tomou o poder em 1964 e governou até 1985, estava tão convicto da ideia de democracia racial, que caracterizava qualquer 
crítica à democracia racial como um "ato de subversão". (AZEVEDO, 1975, p. 53) Além disso, a formação de grupos negros era proibida por ser considerada segregacionista e racista. A intolerância do regime militar a qualquer crítica à democracia racial aumentou com a decisão de não incluir uma questão de cor/ raça nos questionários do censo de 1970. Ironicamente, o regime militar não tinha qualquer razão para temer questões de cor/raça no censo. No ano de 1976, uma pesquisa domiciliar nacional foi realizada com uma questão aberta sobre cor e a população respondeu com 135 tipos diferentes de cor. (BRASIL, 1976) Em resumo, o culto à mestiçagem já tinha se apoderado das identidades raciais dos brasileiros que buscavam alguma categoria racial que não fosse negra para se identificar. Contudo, os militares ainda queriam que o censo de 1980 não tivesse a categoria “cor/raça”. Somente com a abertura democrática, que começou no final dos anos da década de 1970, durante a qual cientistas sociais e ativistas negros fizeram lobby, a questão sobre cor/raça foi restaurada no censo de 1980. Contudo, a reintrodução da questão sobre a cor em todos os questionários dos censos seguintes não alterou a mentalidade nacional sobre a democracia racial tão cuidadosamente cultivada pelo governo.

Logo no início da campanha de "brasilidade" de Getúlio Vargas, os brasileiros passaram a ser expostos a diversos projetos de propaganda governamental que promoviam a brasilidade e a mestiçagem como a única identidade nacional adequada. Isso incluía um programa diário de rádio, a Hora do Brasil. (DAVIS, 1992, p. 249) A influência da brasilidade promovida pelo governo também foi disseminada através de rigorosas orientações a respeito do currículo escolar e dos livros didáticos. Os professores do ensino primário eram orientados a explicar a formação do povo brasileiro como a combinação do "branco, que contribuiu com a língua, os costumes e a religião; o negro, que nos legou a gentileza e o espírito de sacrifício do africano; os indígenas, que nos transmitiram o amor pela liberdade e a ligação com a terra, que são sentimentos inatos do brasileiro". (DAVIS, 1992, p. 252-253) Essa doutrinação continuou na escola secundária e na universidade com o uso do livro Casa Grande e Senzala, de Gilberto Freyre, como um "texto clássico" (no qual ele caracterizou a escravidão brasileira como suave porque o colonizador português seria aberto a aceitar o outro, bem como a contrair matrimônio com pessoas de outras raças e culturas).

$\mathrm{O}$ apego nacional à ideologia da democracia racial também foi facilitado pela preocupação latino-americana com o imperialismo. Sem dúvida, o Brasil estava fora do campo de intervenção política dos Estados Unidos (ao contrário 
de Cuba e Porto Rico no período pós-independência). No entanto, o desejo por investimentos estrangeiros para estimular a modernização e a industrialização foi acompanhado do receio de ser considerada uma nação "vira-lata", sujeita à influência e à interferência externas. Portanto, a atenção nacional para a opinião externa encorajou todos os brasileiros a se considerarem unidos contra qualquer inferioridade imposta a partir do estrangeiro. De fato, o Brasil e a América Hispânica foram descritos por Darién Davis como portadores de um "complexo de inferioridade", contra o qual o patriotismo foi a defesa que resultou na cooptação de minorias étnicas. (DAVIS, 1992, p. 230, 253-260) O conceito de democracia racial da mestiçagem brasileira (e mestizaje na América Hispânica) foi uma fonte útil de orgulho nacional em contraposição às leis Jim Crow nos Estados Unidos. Ao mesmo tempo, a racialização dos espaços patrocinada pelo Estado permitiu que as identidades regionais permanecessem baseadas em raça sem que isso fosse considerado contraditório à noção de democracia racial. Por exemplo, em São Paulo, a identidade paulista, em 1930, foi associada à branquitude da modernidade, indústria e progresso econômico. (WEINSTEIN, 2003, p. 237-262) A identidade paulista, e da região Sul como um todo, foi racialmente associada ao branco em contraposição à negritude e ao atraso da região Nordeste. De fato, logo após Getúlio Vargas assumir o poder, em 1930, o governo do estado de São Paulo declarou guerra contra o governo central porque Vargas indicou um nordestino "atrasado" como governador interino do estado de São Paulo. Durante 83 dias, a partir de 9 de julho de 1932, as tropas do estado de São Paulo lutaram com as tropas federais. A guerra de São Paulo foi caracterizada à época como uma luta para defender "a cultura de homem branco" contra o populismo da "ditadura negra” de Vargas. (WEINSTEIN, 2003, p. 246-247) Inferiores numericamente e mal-equipados, os paulistas negociaram um acordo com o governo central, mas mantiverem sua convicção de que São Paulo deveria ser mais valorizado no país por causa de sua cultura mais civilizada. Mais importante ainda, as diferenças regionais de raça eram compreendidas no Brasil como coexistindo com uma democracia racial, que retratava uma harmonia sobre um pano de fundo de hierarquia racial presumida. Por sua vez, isso ajuda a explicar o duradouro fenômeno das altas taxas de casais compostos por indivíduos da mesma raça em uma democracia racial. (CAULFIELD, 2003, p. 163186; LOWRIE, 1939, p. 684-707)

De fato, uma característica significativa da democracia racial da mestiçagem é seu poder de negar a articulação de diferenças raciais, enquanto apoia 
a existência de uma hierarquia racial e da exclusão socioeconômica como algo que não estaria relacionado à raça, mas à classe. As décadas de políticas de branqueamento patrocinadas pelo Estado asseguraram a subordinação de afro-brasileiros, subordinação que a democracia racial da mestiçagem faz crer ser obra do acaso. Por essa razão, apenas recentemente, a autoridade do mito da democracia racial começou a ser questionada no Brasil e também na América Hispânica. Ainda que as leis de imigração brasileiras e o direito costumeiro de segregação não possam ser comparados diretamente com o contexto da legislação Jim Crow estadunidense, considerar a semelhança dos fins e as consequências das duas formas de regulação racial faz cair por terra o mito de que os governos brasileiros foram inocentes no que diz respeito à regulação racial. Nos capítulos a seguir, detalharei o legado da mestiçagem brasileira e do mestizaje latino-americano, bem como a barreira que esse legado representa para atingir a igualdade racial na região, questões que também ecoam o legado das desigualdades raciais forjadas pela segregação racial baseada na legislação Jim Crow nos Estados Unidos. 